\title{
Article \\ Serum Metabolomics in PCOS Women with Different Body Mass Index
}

\author{
Katarzyna Ożegowska ${ }^{1, * \mathbb{D}}$, Szymon Plewa ${ }^{2} \mathbb{D}$, Urszula Mantaj ${ }^{3}$, Leszek Pawelczyk ${ }^{1}$ and Jan Matysiak $^{2}$ \\ 1 Department of Infertility and Reproductive Endocrinology, Poznan University of Medical Sciences, \\ 61-701 Poznań, Poland; leszek.a.pawelczyk@gmail.com \\ 2 Department of Inorganic and Analytical Chemistry, Poznan University of Medical Sciences, 61-701 Poznań, \\ Poland; szymonplewa1@gmail.com (S.P.); jmatysiak@ump.edu.pl (J.M.) \\ 3 Division of Reproduction, Medical Faculty I, Poznan University of Medical Sciences, 61-701 Poznan, Poland; \\ urszula.mantaj@gmail.com \\ * Correspondence: k.ozegowska@gmail.com
}

Citation: Ożegowska, K.; Plewa, S.; Mantaj, U.; Pawelczyk, L.; Matysiak, J. Serum Metabolomics in PCOS Women with Different Body Mass Index. J. Clin. Med. 2021, 10, 2811. https://doi.org/10.3390/jcm10132811

Academic Editor: Alberto Revelli

Received: 24 May 2021

Accepted: 18 June 2021

Published: 25 June 2021

Publisher's Note: MDPI stays neutral with regard to jurisdictional claims in published maps and institutional affiliations.

Copyright: (c) 2021 by the authors. Licensee MDPI, Basel, Switzerland. This article is an open access article distributed under the terms and conditions of the Creative Commons Attribution (CC BY) license (https:// creativecommons.org/licenses/by/ $4.0 /)$.

\begin{abstract}
Polycystic ovary syndrome (PCOS) is the most prevalent endocrine and metabolic disorder, affecting $5-10 \%$ of women of reproductive age. It results from complex environmental factors, genetic predisposition, hyperinsulinemia, hormonal imbalance, neuroendocrine abnormalities, chronic inflammation, and autoimmune disorders. PCOS impacts menstrual regularities, fertility, and dermatological complications, and may induce metabolic disturbances, diabetes, and coronary heart disease. Comprehensive metabolic profiling of patients with PCOS may be a big step in understanding and treating the disease. The study aimed to search for potential differences in metabolites concentrations among women with PCOS according to different body mass index (BMI) in comparison to healthy controls. We used broad-spectrum targeted metabolomics to evaluate metabolites' serum concentrations in PCOS patients and compared them with healthy controls. The measurements were performed using high-performance liquid chromatography coupled with the triple quadrupole tandem mass spectrometry technique, which has highly selective multiple reaction monitoring modes. The main differences were found in glycerophospholipid concentrations, with no specific tendency to up-or down-regulation. Insulin resistance and elevated body weight influence acylcarnitine C2 levels more than PCOS itself. Sphingomyelin (SM) C18:1 should be more intensively observed and examined in future studies and maybe serve as one of the PCOS biomarkers. No significant correlations were observed between anthropometric and hormonal parameters and metabolome results.
\end{abstract}

Keywords: polycystic ovary syndrome; metabolome; metabolic disturbances; body mass index; insulin resistance; metabolic pathways

\section{Introduction}

Polycystic ovary syndrome (PCOS) is one of the most prevalent endocrine and metabolic disorders. It results, i.e., from complex and poorly understood environment factors, genetic predisposition, hyperinsulinemia, hormonal imbalance, neuroendocrine abnormalities, chronic inflammation, and autoimmune disorders [1-3]. However, it is mainly characterized by clinical and biochemical hyperandrogenism, ovulatory dysfunction, and the polycystic morphology of the ovaries on the ultrasound [4]. Therefore, various classifications are proposed to diagnose PCOS: National Institutes of Health Criteria (NIH), defined in 1990, include the presence of clinical and/or biochemical hyperandrogenism and oligo/amenorrhea anovulation [5].

In 2003 the European Society of Human Reproduction and Embryology / American Society for Reproductive Medicine Rotterdam consensus (ESHRE/ASRM) evolved NIH criteria, requiring two of three features: clinical and/or biochemical hyperandrogenism, 
anovulation or oligo-ovulation, and polycystic ovarian morphology (PCOM) on the ultrasound [6]. The Rotterdam criteria are controversial since fulfilling two of three diagnostic criteria implies that PCOS can be diagnosed in the absence of androgen excess or menstrual irregularity [7]. In 2006, the Androgen Excess Society (AES) reviewed existing data on phenotypic expression. They concluded that there was conflicting evidence supporting the presence of such features as insulin resistance and metabolic disturbances in women with polycystic ovaries and ovulatory dysfunction, but without clinical or biochemical signs of hyperandrogenism. Thus, the AES considered that androgen excess is a central feature in the development and pathogenesis of polycystic ovary syndrome and proposed the definition that androgen excess should be present and accompanied by oligomenorrhea or PCOM or both of them. In addition to those features, exclusion of other androgen excess causes (i.e., non-classical congenital adrenal hyperplasia (NC-CAH), Cushing's syndrome, androgen-secreting tumors, hyperprolactinemia, thyroid diseases, drug-induced androgen excess, disorders) is essential for the diagnosis [8]. It affects $5-21 \%$ of women of reproductive age [1,9], depending on the different geographic regions, as well as the criteria used to diagnose the syndrome: $5 \%$ to $10 \%$ according to NIH 1990 criteria; $10 \%$ to $15 \%$ according to the AE-PCOS 2006 criteria, and 6\% to 21\% by ESHRE/ASRM 2003 criteria [10-15].

In 2018, Teede et al. proposed an international evidence-based guideline for the assessment and management of PCOS that encourages Rotterdam criteria in diagnosing PCOS [16].

Insulin resistance (IR) and hyperandrogenemia are deemed to be the most basic pathophysiological changes in PCOS. In addition, PCOS impacts menstrual regularities, fertility, and dermatological complications and may induce metabolic disturbances, diabetes, and coronary heart disease $[17,18]$.

A vast group of PCOS patients is overweight or obese, leading to abdominal and visceral obesity $[19,20]$. Independently of obesity, those women often (50-70\%) present with IR and compensatory hyperinsulinemia $[19,21]$. Researchers have attempted to determine whether biomarkers might use as predictive markers for different phenotypes.

In 2012, the NIH consensus panel proposed to classify PCOS according to phenotypes. Phenotype A (full-blown syndrome PCOS: clinical or biochemical hyperandrogenism (HA)+ ovulatory dysfunction (OD)+polycystic ovarian morphology (PCOM) (HA + OD + PCO). Phenotype B (non-PCO PCOS: HA + OD) includes hyperandrogenism (HA) and ovulatory dysfunction (OD). Phenotype C (ovulatory PCOS: HA + PCOM) includes hyperandrogenism (HA) and polycystic ovaries (PCOM). Phenotype D (non-hyperandrogenic PCOS: OD + PCOM) includes ovulatory dysfunction (OD) and polycystic ovaries (PCOM) [22].

Homeostatic model assessment of insulin resistance (HOMA-IR) [23], the testosteroneto-androstenedione ratio [24], free androgen index [25], serum anti-mullerian hormone $(\mathrm{AMH})$ level [26] was found to be potential biomarkers for predicting and diagnosing PCOS. Thus, it is essential to understand the disease's pathogenesis better and identify its potential biomarkers, which may help us diagnose it correctly, seek prevention agents, and effectively manage PCOS symptoms and complications. Comprehensive metabolic profiling of patients with PCOS may be a big step in understanding and treating the disease.

Metabolomics is a rapidly advancing field of discovery science aimed at furthering knowledge of the biological consequences of metabolic changes from a single cell to the whole organism [27]. As a method of analysis, it allows the investigation of underlying mechanisms that control biological functions and the expression of different phenotypes of patients [28]. Combined with genomic and proteomic data, it might show both the organism's physiological and pathological state [29]. In metabolomics, there are two approaches: untargeted, which usually analyzes the numbers of metabolites in the samples without a priori knowledge about these compounds, and the second-targeted. The targeted metabolomics is typically used for qualitative and quantitative analysis of selected metabolites or metabolites. Today it is possible to analyze even over the hundred metabolites from different chemical classes using a targeted approach. Such an approach might be helpful to identify and quantify multiple small-molecule metabolites such as amino acids, 
lipids, nucleotides, and organic acids in biological samples. Compared to proteomics, transcriptomics, and genomics, it is considered closer to the actual phenotype and gives us the most helpful information that may serve as a utensil for personalized diagnosis, treatment, and disease monitoring [30,31]. The analysis of metabolic differences between patients and healthy controls can indicate potential biomarkers of the disease, lead to a more proper understanding of its pathogenesis, and help control and evaluate the diagnostic and treatment methods [32]. Metabolites can be intrinsic, resulting from normal cellular physiology, or extrinsic, with the influence of exogenously administered drugs or interventions [33]. The Human Metabolome Database (HMDB) contains up to May 2020 114,186 metabolite entries, including both water-soluble and lipid-soluble metabolites, as well as metabolites that would be regarded as either abundant $(>1 \mu \mathrm{M})$ or relatively rare $(<1 \mathrm{nM})$. Additionally, 5702 protein sequences are linked to these metabolite entries.

Because PCOS is a complex disorder, complicated with androgen excess, abdominal obesity, IR, and various metabolic disturbances, which leads to a different manifestation of the disease and presentation with different phenotypes [34], there is a need to examine the exact origin of these metabolic alterations and therefore to seek for new metabolic biomarkers for PCOS [35]. The complex metabolic pathways involved in the occurrence of PCOS and its symptoms are not well understood. Some studies evaluated carbohydrate, lipid, and protein metabolism in this group of patients [36-38].

The presented study aimed to evaluate metabolites in average weight and obese patients with PCOS diagnosis and compare the results with a healthy population, using the well-established high-throughput Liquid Chromatography-Mass Spectrometry (LCMS/MS) methodology with a proven interlaboratory reproducibility.

\section{Materials and Methods}

\subsection{Study Subjects}

We included into the study patients diagnosed with PCOS according to Rotterdam criteria [8]: (1) the presence of clinical and/or biochemical signs of hyperandrogenism (Ferriman-Gallwey score $\geq 8$; testosterone level $>0.5 \mathrm{ng} / \mathrm{mL}$ ); (2) oligo- or anovulation ( $<8$ cycles/year) and/or polycystic ovaries morphology on the ultrasound (ovarian volume > than $10 \mathrm{~mL}$ provided excellent specificity for PCOS in a majority of studies and used 12 or more follicles of 2 to $9 \mathrm{~mm}$ ) [39]. In all the patients, congenital adrenal hyperplasia was excluded by evaluating morning follicular phase 17-hydroxyprogesterone $(<2 \mathrm{ng} / \mathrm{mL})$, hyperprolactinemia was excluded by morning prolactin levels. Cushing's syndrome and androgen-secreting tumors were excluded based on clinical evaluation.

PCOS patients were divided into two groups according to BMI. According to the World Health Organization (WHO), average body weight is considered BMI $\geq 18.5$ to $24.9 \mathrm{~kg} / \mathrm{m}^{2}$. As abnormal BMI, WHO considers overweight patients with BMI $\geq 25$ to $29.9 \mathrm{~kg} / \mathrm{m}^{2}$ and obesity with BMI $\geq 30 \mathrm{~kg} / \mathrm{m}^{2}$ [40].

We divided the study group into abnormal bodyweight group (PCOS-1) with 34 patients with diagnosed PCOS and BMI $\geq 25 \mathrm{~kg} / \mathrm{m}^{2}$ and PCOS- 2 with 32 women with PCOS and normal BMI $\left(<25 \mathrm{~kg} / \mathrm{m}^{2}\right)$.

We matched those two groups with age-matched healthy controls $(n=11)$, which consisted of average women who came for a routine check-up in our hospital's outpatients' clinic. All the patients we recruited at the Gynecological and Obstetrical Hospital of Poznan University of Medical Sciences from 2018 to 2019.

The control group consisted of healthy volunteers with regular menstrual cycles, no clinical or biochemical hyperandrogenism, routine ovarian ultrasonography, no history of endocrine or autoimmune disorders, and no pelvic history surgery. In all the groups, we excluded patients with:

- Neoplasm

- Kidney failure

- Hypertension, dyslipidemia, diabetes mellitus

- Other endocrinopathies 
- Hormonal treatment

- Drugs influencing the glycemic levels

\subsection{Patients Evaluation}

Medical and family history we investigated for all patients. In addition, clinical examination was performed, including measurement of body weight, height, waist circumference (WC) at the midpoint between the lateral iliac crest and the lowest rib margin at the end of normal expiration, waist to hip ratio (WHR), and hip circumference (HC) measured at the broadest level of the greater trochanters. Body mass index (BMI) was calculated as weight in kilograms divided by the square of height in meters $\left(\mathrm{kg} / \mathrm{m}^{2}\right)$. According to the World Health Organization categories, being overweight was defined as having a BMI of $25.0-29.9 \mathrm{~kg} / \mathrm{m}^{2}$, and obesity was described as a BMI of $\geq 30.0 \mathrm{~kg} / \mathrm{m}^{2}$ [40]. All the patients enrolled in the study were evaluated during the menstrual cycle's early follicular phase (days 3-5) after discontinuing antidiabetic and contraceptive agents for $\geq$ three months.

\section{Methodology}

\subsection{Biochemical and Hormonal Analysis}

Blood samples for biochemical and hormonal analysis were drawn from the antecubital vein between 8 and $10 \mathrm{AM}$ following a 12-h overnight fast. The serum/plasma specimens were stored at $-70{ }^{\circ} \mathrm{C}$. The $75 \mathrm{~g}$ oral glucose tolerance test was performed in all patients; blood samples were obtained at baseline and at 1 and $2 \mathrm{~h}$ postprandially to determine glucose and insulin at each time point. Serum concentrations of estradiol (E2), luteinizing hormone (LH), follicle-stimulating hormone (FSH), prolactin (PRL), total testosterone (T), dehydroepiandrostendion sulfate (DHEA-S), sex-hormone-binding globulin (SHBG), thyroid-stimulating hormone TSH, and thyroxine (fT4) were measured by immunoenzymatic assay (ELISA Kit, Invitrogen, Thermo Fisher Scientific, USA). All biochemical, hormonal and standard coagulation panel analyses were performed in the university hospital's accredited laboratory, holding certificates of quality management ISO 9000.

\subsection{Metabolome}

We collected serum samples into $7.5 \mathrm{~mL}$ S-Monovette (Sarstedt AG\&Co., Nümbrecht, Germany) tubes with a clotting activator to evaluate metabolome. After $30 \mathrm{~min}$ of room temperature storage, samples were centrifuged ( $15 \mathrm{~min}$. at $4000 \mathrm{rpm}$ ), serum was aliquoted, frozen, and stored at $-80^{\circ} \mathrm{C}$. Before analysis, the serum samples were thawed and centrifuged at $2800 \times g$ for $5 \mathrm{~min}$.

The AbsoluteIDQ p180 kit (Biocrates Life Sciences AG, Innsbruck, Austria) was used to evaluate the broad spectrum of metabolites in samples. This high-throughput methodology with a proven interlaboratory reproducibility [41] enables the analysis of up to 188 metabolites from a different class of chemical compounds. The analyses of amino acids and biogenic amines required chromatographic separation accomplished by LC-MS/MS experiment. In turn, the analysis of acylcarnitine, hexoses, and lipids was accomplished by the flow injection analysis (FIA-MS/MS) experiment performed after the LC-MS/MS experiment.

The sample preparation procedure was performed step-by-step by the manufacturer's specifications. Firstly, calibration standards, quality control samples, and internal standards mix dissolved inappropriate water and shook to mix. Next, the $10 \mu \mathrm{L}$ of the standard internal mix was pipetted to each well of the 96-well plate, followed by pipetting $10 \mu \mathrm{L}$ of serum-sample and drying the plate under nitrogen flow. Afterwards, $50 \mu \mathrm{L}$ of $5 \%$ phenylisothiocyanate was added, and the plate was incubated for $20 \mathrm{~min}$, after which drying for $60 \mathrm{~min}$ under nitrogen was applied. Then, extraction with $300 \mu \mathrm{L}$ of $5 \mathrm{mM}$ methanolic solution of ammonium acetate was carried out. The extraction was performed by shaking the plate with extraction solvent for $30 \mathrm{~min}$ at $450 \mathrm{rpm}$, and then nitrogen flow was used for transferring the extract to the capture plate. In the end, the extract was split 
and diluted with appropriate solvents, giving two separate plates, first for LC-MS/MS experiment, the second plate for the FIA experiment.

The 1260 Infinity high-performance liquid chromatography (Agilent Technologies, Santa Clara, CA, USA) coupled to a triple quadrupole tandem mass spectrometer (SCIEX, Framingham, MA, USA) was used for metabolite quantitation. Chromatographic separation was achieved by application the ZORBAX Eclipse XDB-C18 $(3.0 \times 100 \mathrm{~mm}, 3.5 \mu \mathrm{m})$ column (Agilent Technologies, Santa Clara, CA, USA), with a pre-column $(\mathrm{C} 18,4.0 \times 3.0 \mathrm{~mm})$ SecurityGuard (Phenomenex, Torrance, CA, USA). The liquid chromatography and mass spectrometer were operated, and the data was acquired under the control of Analyst software version 1.6 (Sciex, Framingham, MA, USA). Biocrates MetIDQ software (Biocrates Life Sciences AG, Innsbruck, Austria) was used for data processing.

\subsection{Statistical Analysis}

All statistical analyses were performed using the Statistica version 10 PL software (StatSoft, Inc., Tulsa, OK, USA). The distribution of continuous variables was evaluated using the Shapiro-Wilk test. Because of the absence of normal distribution, nonparametric testing was performed using Mann-Whitney U and Kruskal-Wallis tests. Continuous variables were expressed as medians (interquartile range (IQR), 25-75th percentile) unless otherwise indicated. $p<0.05$ was considered a statistically significant difference between medians.

In statistical testing of determined metabolites, unsupervised multivariate principal component analysis (PCA) was used to find potential outliers and examine clustering or separation trends. In addition, for comparing patients with PCOS and the control group, the volcano plot analysis was carried out. For this analysis, which is a combination of fold change and t-tests, the following thresholds were set: 1.25 and 0.05 for fold change and $p$-value, respectively. Moreover, univariate ROC curve analysis was performed for searching for the highest discriminating potential of determining compounds. Additionally, the correlation analysis between metabolome results and clinical parameters was carried out. Finally, the Metaboanalyst web portal was applied for targeted metabolomics data analysis and visualization [42].

The Ethics Committee approved the study protocol of Poznań University of Medical Sciences (Poznan, Poland). Approval number 741/20 (4.11.2020). Written consent was obtained from all the subjects.

\section{Results}

In Table 1, we present characteristics of the whole PCOS group compared with controls. Patients were age-matched with a median age of 28.5 (28.0-32.0) in PCOS patients and 26 (24.7-30.5) in the control group. We see a significant difference in the patients' anthropometric parameters (BMI, WC, HC, WHR) and metabolic parameters (fasting glucose and insulin levels, HOMA-IR, complete lipid profile).

When we divided PCOS patients into groups according to BMI level and compared them with a control group, we notice significant differences in similar parameters (Table 2). Patients did not differ according to age, but we may detect a substantial elevation of BMI, WC, HC, and WHR in PCOS-1 than PCOS-2 and controls. In addition, the metabolic profile (glucose levels, insulin levels, HOMA-IR, $\mathrm{HbA} 1 \% \mathrm{C}$ ) was significantly different between PCOS groups than in controls. PCOS-Obese patients also had the most abnormal lipid profile. Interestingly PCOS-2 patients and controls did not differ at all following C-reactive protein (CRP), but it was significantly higher in the PCOS-obese population. 
Table 1. Characteristic and comparison of whole PCOS group and controls.

\begin{tabular}{cccc}
\hline & \multicolumn{2}{c}{ Median (25th-75th Percentile) } & \\
\hline & PCOS $(\boldsymbol{n}=\mathbf{6 6})$ & $\begin{array}{c}\text { Control Group } \\
(\boldsymbol{n}=\mathbf{1 1})\end{array}$ & $p$-Value * \\
\hline Age (years) & $28.5(28.0-32.0)$ & $26(24.7-30.5)$ & 0.56 \\
BMI $\left(\mathrm{kg} / \mathrm{m}^{2}\right)$ & $27.4(22.5-32.9)$ & $21.6(19.4-41.5)$ & 0.02 \\
Systolic BP $(\mathrm{mmHg})$ & $111.0(100.0-120.0)$ & $108(100-116)$ & 0.4 \\
Diastolic BP (mmHg) & $70.0(60.0-80.0)$ & $70(65-71)$ & 0.6 \\
WC (cm) & $88.6(75.0-103.4)$ & $71.6(66.5-74.8)$ & 0.001 \\
HC (cm) & $107.0(95.3-116.8)$ & $95.4(91.2-99.8)$ & 0.01 \\
WHR & $0.8(0.8-0.9)$ & $0.75(0.71-0.8)$ & 0.0005 \\
Fasting insulin & $11.6(8.6-17.9)$ & $6.5(4.5-8.2)$ & 0.0003 \\
( $\mu$ IU /mL) & & & 0.001 \\
Fasting glucose & $92.7(87.0-97.0)$ & $81.8(74.3-90)$ & 0.0001 \\
$(\mathrm{mg} / \mathrm{dL})$ & $2.7(2.0-4.2)$ & $1.3(0.9-1.6)$ & 0.1 \\
HOMA-IR & $5.2(4.9-5.4)$ & $5.0(4.8-5.1)$ & 0.02 \\
HBA1\%C & $172.4(154.0-196.4)$ & $153.9(143.3-166.8)$ & 0.04 \\
TC (mg/dL) & $58.9(49.1-72.1)$ & $70.8(62.0-80.5)$ & 0.003 \\
HDL (mg/dL) & $92.5(73.0-113.4)$ & $71.4(61.7-81.9)$ & 0.0006 \\
LDL (mg/dL) & $92.2(69.8-147.2)$ & $58.3(47.6-58.8)$ & 0.2 \\
TG (mg/dL) & $0.89(0.33-2.9)$ & $0.8(0.2-1.3)$ & 0.2 \\
CRP (mg/L) & $190.0(109.0-299.0)$ & $254.3(209.0-303.0)$ & 0.4 \\
D-DIMER (ng/mL) & $2.9(2.5-3.6)$ & $2.8(2.4-3.2)$ & \\
Fibrinogen (g/L) & & &
\end{tabular}

${ }^{*}$ Mann-Whitney, BMI—body mass index, BP—blood pressure, WC—waist circumference, HC—hip circumference, WHR - waist-to-hip ratio, HOMA-IR-Homeostatic Model Assessment for Insulin Resistance, HbA1\%Cglycosylated hemoglobin, TC — total cholesterol, HDL—high-density lipoprotein cholesterol, LDL-low-densitylipoprotein cholesterol, TG—-triglycerides, CRP—c-reactive protein.

Table 2. Characteristic and comparison PCOS-1 vs. PCOS-2 vs. controls.

\begin{tabular}{|c|c|c|c|c|c|}
\hline \multicolumn{6}{|c|}{ Median (25th-75th Percentile) } \\
\hline Variable & $\begin{array}{c}\text { PCOS-1 }(n=34) \\
{[1]}\end{array}$ & $\begin{array}{c}\text { PCOS-2 }(n=32) \\
{[2]}\end{array}$ & $\begin{array}{c}\text { Control }(n=11) \\
{[3]}\end{array}$ & $p$-Value * & $p$-Value \# \\
\hline Age (years) & $28.5(27-30)$ & $30.8(28.0-34.0)$ & $26(24.7-30.5)$ & 0.6 & \\
\hline BMI $\left(\mathrm{kg} / \mathrm{m}^{2}\right)$ & $32.2(28.7-35.8)$ & $24.0(20.7-24.8)$ & $21.6(19.4-41.5)$ & $<0.0001$ & $\begin{array}{c}1 \text { vs. } 3<0.0001 \\
1 \text { vs. } 2<0.0001 \\
2 \text { vs. } 31.0\end{array}$ \\
\hline $\begin{array}{c}\text { Systolic BP } \\
(\mathrm{mmHg})\end{array}$ & $115(90-150)$ & $110.1(100-120.0)$ & $108(100-116)$ & 0.5 & \\
\hline $\begin{array}{l}\text { Diastolic BP } \\
(\mathrm{mmHg})\end{array}$ & $70(60-100)$ & $70.6(60.0-80.0)$ & $70(65-71)$ & 0.8 & \\
\hline $\mathrm{WC}(\mathrm{cm})$ & $102.6(82.6-147.5)$ & $74.3(67.0-80.2)$ & $71.6(66.5-74.8)$ & $<0.0001$ & $\begin{array}{c}1 \text { vs. } 3<0.0001 \\
1 \text { vs. } 2<0.0001 \\
2 \text { vs. } 31.0 \\
1 \text { vs. } 3<0.0001\end{array}$ \\
\hline $\mathrm{HC}(\mathrm{cm})$ & $116(105.2-144)$ & $92.9(88.0-98.0)$ & $95.4(91.2-99.8)$ & $<0.0001$ & $\begin{array}{c}1 \text { vs. } 2<0.0001 \\
2 \text { vs. } 31.0 \\
1 \text { vs. } 3<0.0001\end{array}$ \\
\hline WHR & $0.88(0.72-1.17)$ & $0.8(0.75-0.84)$ & $0.75(0.71-0.8)$ & $<0.0001$ & $\begin{array}{c}1 \text { vs. } 2<0.0001 \\
2 \text { vs. } 31.0\end{array}$ \\
\hline $\begin{array}{l}\text { Fasting insulin } \\
\quad(\mu \mathrm{IU} / \mathrm{mL})\end{array}$ & $16.7(4.5-66.3)$ & $10.0(6.7-12.0)$ & $6.5(4.5-8.2)$ & $<0.0001$ & $\begin{array}{c}1 \text { vs. } 30.0001 \\
1 \text { vs. } 20.007 \\
2 \text { vs. } 3<0.0001\end{array}$ \\
\hline $\begin{array}{l}\text { Fasting glucose } \\
\qquad(\mathrm{mg} / \mathrm{dL})\end{array}$ & $92.7(85.7-97.0)$ & $91.1(87.6-96.4)$ & $81.8(74.3-90)$ & 0.005 & $\begin{array}{l}1 \text { vs. } 30.86 \\
1 \text { vs. } 21.0 \\
2 \text { vs. } 30.8\end{array}$ \\
\hline
\end{tabular}


Table 2. Cont.

\begin{tabular}{|c|c|c|c|c|c|}
\hline \multicolumn{6}{|c|}{ Median (25th-75th Percentile) } \\
\hline Variable & $\begin{array}{c}\text { PCOS-1 }(n=34) \\
{[1]}\end{array}$ & $\begin{array}{c}\text { PCOS-2 }(n=32) \\
{[2]}\end{array}$ & $\begin{array}{c}\text { Control }(n=11) \\
{[3]}\end{array}$ & $p$-Value * & $p$-Value ${ }^{\#}$ \\
\hline HOMA-IR & $4.6(2.7-5.6)$ & $2.3(1.5-2.7)$ & $1.3(0.9-1.6)$ & $<0.0001$ & $\begin{array}{c}1 \text { vs. } 3<0.0001 \\
1 \text { vs. } 20.003 \\
2 \text { vs. } 3<0.0001 \\
1 \text { vs. } 3<0.0001\end{array}$ \\
\hline HBA $1 \% \mathrm{C}$ & $5.4(5.1-5.6)$ & $5.0(4.8-5.2)$ & $5.0(4.8-5.1)$ & 0.003 & $\begin{array}{c}1 \text { vs. } 2<0.0001 \\
2 \text { vs. } 31.0 \\
1 \text { vs. } 20.097\end{array}$ \\
\hline $\mathrm{TC}(\mathrm{mg} / \mathrm{dL})$ & $181.1(163.6-191.1)$ & $177.2(144.8-200.4)$ & $153.9(143.3-166.8)$ & 0.03 & $\begin{array}{l}1 \text { vs. } 30.001 \\
2 \text { vs. } 30.002\end{array}$ \\
\hline HDL (mg/dL) & $50.2(38.9-56.5)$ & $72.9(59.2-83.1)$ & $70.8(62.0-80.5)$ & $<0.0001$ & $\begin{array}{c}1 \text { vs. } 2<0.0001 \\
1 \text { vs. } 3<0.0001 \\
2 \text { vs. } 31.0 \\
1 \text { vs. } 20.03\end{array}$ \\
\hline $\mathrm{LDL}(\mathrm{mg} / \mathrm{dL})$ & $106.9(83.3-125.9)$ & $86.8(60.8-106.9)$ & $71.4(61.7-81.9)$ & 0.0002 & $\begin{array}{c}1 \text { vs. } 30.001 \\
2 \text { vs. } 30.4 \\
1 \text { vs. } 20.001\end{array}$ \\
\hline $\mathrm{TG}(\mathrm{mg} / \mathrm{dL})$ & $151.9(90.8-200.5)$ & $87.4(55.6-116.7)$ & $58.3(47.6-58.8)$ & $<0.0001$ & $\begin{array}{c}1 \text { vs. } 3<0.0001 \\
2 \text { vs. } 30.04 \\
1 \text { vs. } 20.003\end{array}$ \\
\hline $\mathrm{CRP}(\mathrm{mg} / \mathrm{L})$ & $2.9(0.8-4.2)$ & $0.8(0.12-0.9)$ & $0.8(0.2-1.3)$ & 0.0003 & $\begin{array}{c}1 \text { vs. } 30.003 \\
2 \text { vs. } 31.0\end{array}$ \\
\hline $\begin{array}{l}\text { D-DIMER } \\
\text { (ng/mL) }\end{array}$ & $244.3(113.0-327.0)$ & $196.2(96.0-290.0)$ & $254.3(209.0-303.0)$ & 0.23 & \\
\hline Fibrinogen $(\mathrm{g} / \mathrm{L})$ & $3.4(2.8-3.8)$ & $2.7(2.27-2.9)$ & $2.8(2.4-3.2)$ & 0.004 & $\begin{array}{c}1 \text { vs. } 20.01 \\
1 \text { vs. } 31.0 \\
2 \text { vs. } 30.01\end{array}$ \\
\hline
\end{tabular}

* Kruskal-Wallis, " Bonferroni correction test, BMI—body mass index, BP—blood pressure, WC—waist circumference, HC—hip circumference, WHR - waist-to-hip ratio, HOMA-IR-Homeostatic Model Assessment for Insulin Resistance, HbA1\%C—glycosylated hemoglobin, TC—-total cholesterol, HDL—high-density lipoprotein cholesterol, LDL—low-density-lipoprotein cholesterol, TG—triglycerides, CRP-creactive protein.

In Table 3 we present the hormonal analysis of the three groups. We may notice the elevation of testosterone (T) levels in both PCOS groups (median $>0.5 \mathrm{ng} / \mathrm{mL}$ ) as well as typical for hyperandrogenism drop in the level of sex-hormone globulin (SHBG) in PCOS populations.

Table 3. Hormonal analysis: PCOS-1 vs. PCOS-2 vs. controls.

\begin{tabular}{ccccc}
\hline \multicolumn{5}{c}{ Median (25th-75th Percentile) } \\
\hline Variable & PCOS-1 $(\boldsymbol{n}=\mathbf{3 4})$ & PCOS-2 $(\boldsymbol{n = 3 2 )}$ & Control $(\boldsymbol{n}=\mathbf{1 1})$ & $p$-Value * \\
\hline FSH $(\mathrm{mIU} / \mathrm{mL})$ & $6.0(4.7-6.7)$ & $6.4(5.6-7.6)$ & $5.1(4.0-6.3)$ & 0.08 \\
LH $(\mathrm{mIU} / \mathrm{mL})$ & $11.8(7.8-14.4)$ & $15.6(11.2-19.0)$ & $6.0(5.0-7.1)$ & $p<0.001$ \\
E2 $(\mathrm{pg} / \mathrm{mL})$ & $75.6(43.2-60.8)$ & $66.3(45.2-76.8)$ & $88.0(68.0-99.0)$ & 0.75 \\
PRL $(\mathrm{ng} / \mathrm{mL})$ & $13.0(8.4-15.5)$ & $12.3(7.7-13.0)$ & $13.8(6.8-16.4)$ & 0.78 \\
T $(\mathrm{ng} / \mathrm{mL})$ & $0.7(0.4-0.8)$ & $0.54(0.42-0.63)$ & $0.43(0.3-4.8)$ & 0.03 \\
DHEA-S $(\mathrm{ug} / \mathrm{dL})$ & $277.0(202.0-350.0$ & $237.0(198.0-322.0)$ & $140.0(122.0-171.0$ & 0.04 \\
TSH $(\mu \mathrm{H} / \mathrm{mL})$ & $1.9(1.3-2.5)$ & $1.8(1.2-2.4)$ & $1.6(1.2-2.1)$ & 0.85 \\
SHBG $(\mathrm{nmol} / \mathrm{L})$ & $31.1(18.2-48.4)$ & $45.5(42.8-47.6)$ & $56.0(41.1-68.4$ & $p<0.001$ \\
17-OH-P $(\mathrm{ng} / \mathrm{mL})$ & $0.9(0.7-1.0)$ & $0.8(0.6-0.9)$ & $0.7(0.6-0.8)$ & 0.8 \\
\hline
\end{tabular}

* Values are expressed as medians (interquartile range); $p$-values were calculated using the Mann-Whitney post hoc U-test with Bonferroni adjustment; $p<0.05$ was considered statistically significant. DHEA-Sdehydroepiandrosterone sulfate; E2 - estradiol; FSH—follicle-stimulating hormone; PRL—prolactin; SHBGsex-hormone-binding globulin; T-testosterone; TSH—-thyroid-stimulating hormone; 17-OH-P-17-hydroxyprogesterone. 


\section{1. $P C A$}

We used the unsupervised multivariate principal component analysis (PCA) to examine clustering or separation trends and find potential outliers. Figure 1 showed a separation tendency among data from the control group and the whole PCOS population. We may observe on this figure some partial separation of samples (outliners) in the PCOS group that differ significantly from the rest of the group. Interestingly, BMI, age, hormonal and lipid profile, anthropometric parameters did not vary between those outliners and the rest of the PCOS group and therefore probably had no impact on sample clustering.

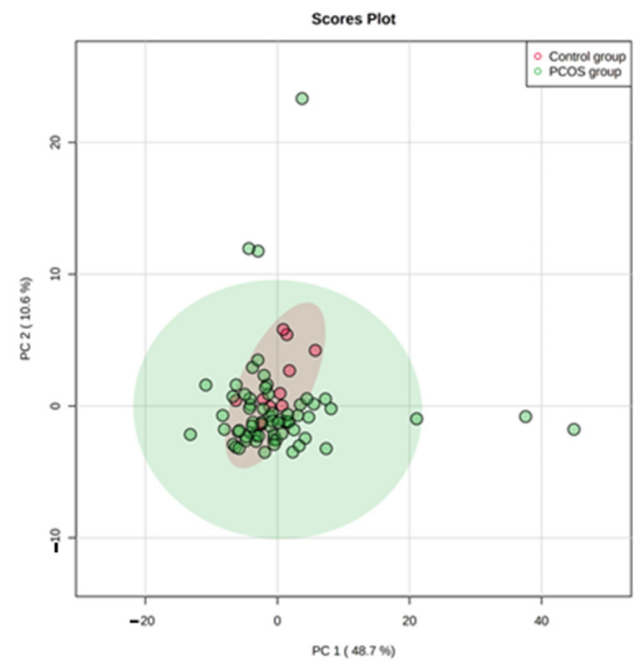

A

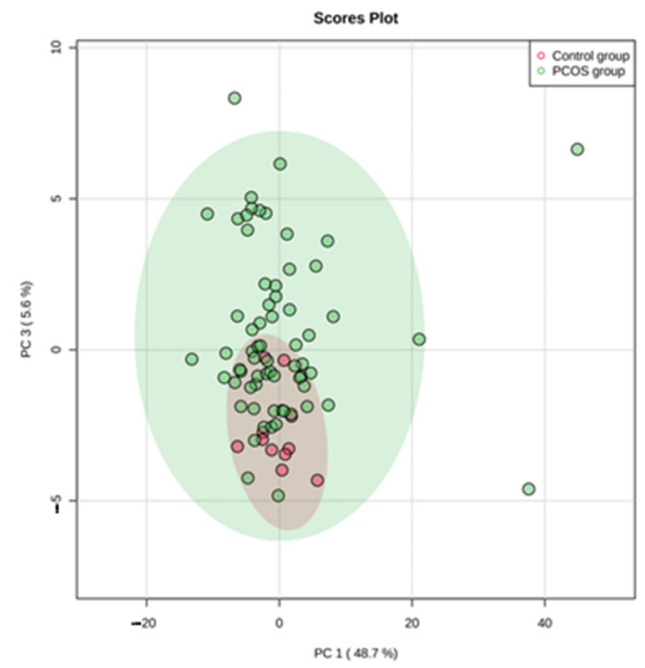

B

Figure 1. The unsupervised multivariate principal component analysis (PCA) of the studied metabolites in the PCOS and control groups. The plots represent the first principal component (PC1) against the second principal component (PC2) (B) and the first principal component (PC1) against the third principal component (PC3) (A).

The unsupervised multivariate principal component analysis (PCA) of the studied metabolites in the PCOS and control groups.

We analyzed PCA results in the next step of the study after dividing them into PCOS-1, PCOS-2, and control groups (Figures 2 and 3).

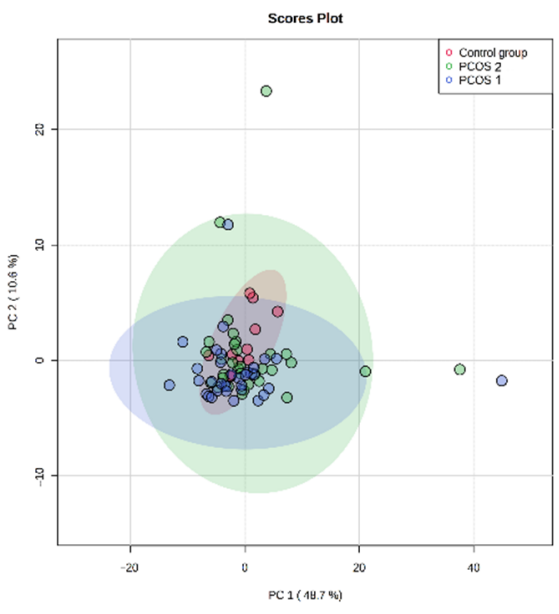

A

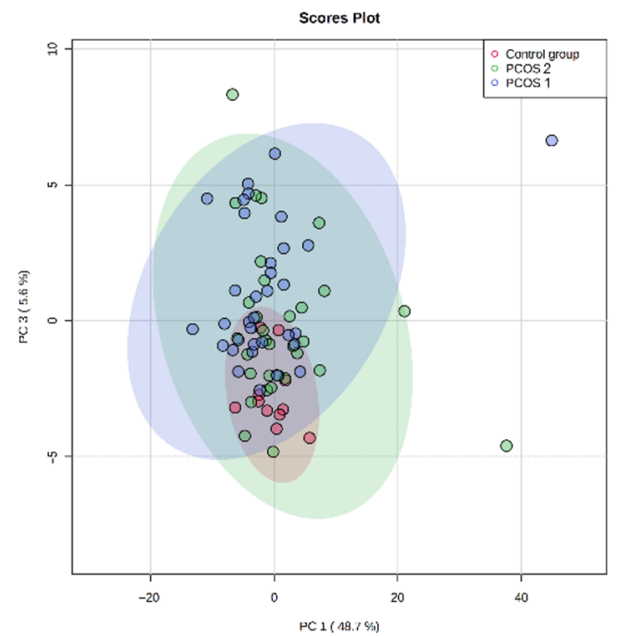

B

Figure 2. The unsupervised multivariate principal component analysis (PCA) of the studied metabolites in the PCOS-1, PCOS-2, and control groups. The plots represent the first principal component (PC1) against the second principal component (PC2) (A) and the first principal component (PC1) against the third principal component (PC3) (B). 


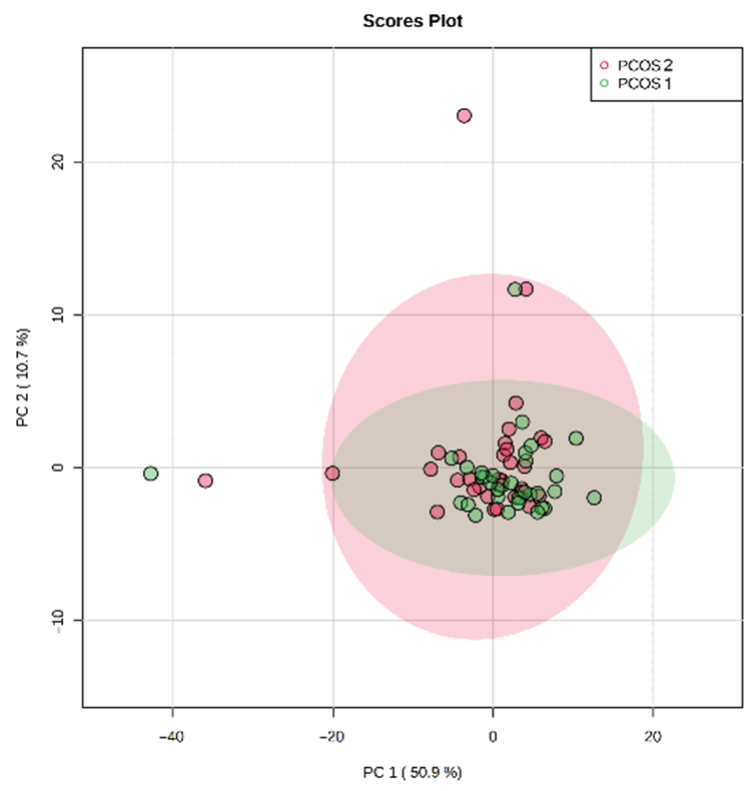

A

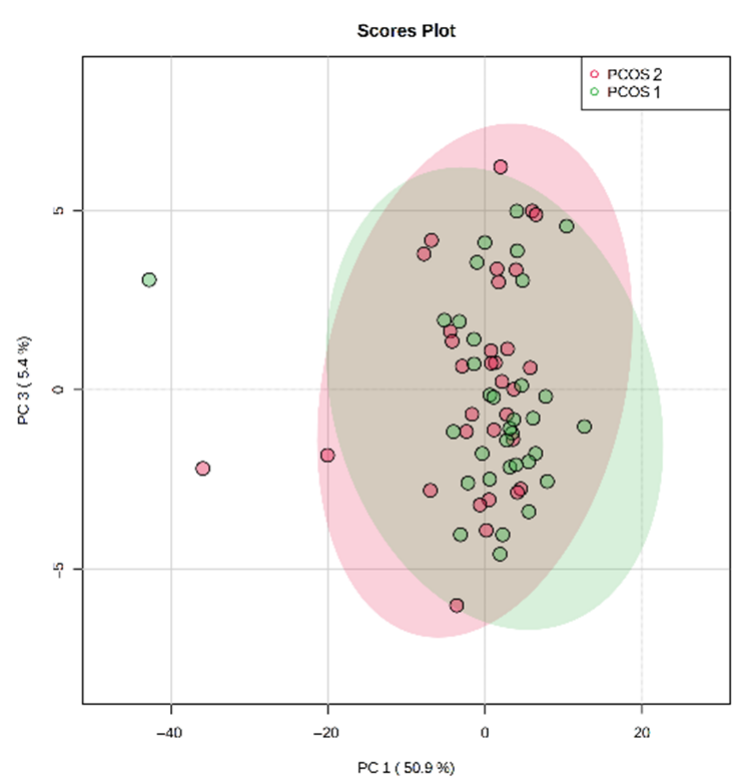

B

Figure 3. The unsupervised multivariate principal component analysis (PCA) of the studied metabolites in the PCOS-1 and PCOS-2 groups. The plots represent the first principal component (PC1) against the second principal component (PC2) (A) and the first principal component (PC1) against the third principal component (PC3) (B).

Similarly, we noticed increased concentration within the PCOS groups compared to healthy controls. In addition, we observed some outliners in both PCOS groups. It seems that not the bodyweight but PCOS itself alternates the metabolic profile of patients. When we analyze the results presented in Figures 1-3, we also observe that the control group metabolites have a more visible tendency to concentrate. The PCOS results in both groups seem to spread more intensively and have more outliners. It indicates that the healthy controls have a more constant metabolic profile than all PCOS patients.

\subsection{Univariate Tests}

Comparing patients with PCOS and the control group, 30 features from the metabolome dataset had $p$ values below 0.05 . In the volcano plot, which is the combination of fold change and t-tests, the following variables met the set criteria (fold change threshold 1.25 and the $p$-value threshold 0.05) when comparing the whole PCOS population to the control group: phosphatidylcholine acyl-acyl C36:5 (PC aa C36:5); phosphatidylcholine acyl-alkyl C40:5 (PC ae C40:5); phosphatidylcholine acyl-acyl C38:3 (PC aa C38:3); phosphatidylcholine acyl-alkyl C38:6 (PC ae C38:6); phosphatidylcholine acyl-acyl C36:4 (PC aa C36:4); sphingomyelin C18:1 (SM C18:1) (significantly up-regulated in samples from PCOS patients) and methionine sulfoxide (Met-SO); lysophosphatidylcholine acyl C 18:2 (lysoPC a C18:2); phosphatidylcholine acyl-alkyl C38:2 (PC ae C38:2); lysophosphatidylcholine acyl C17:0 (lysoPC a C17:0); phosphatidylcholine acyl-alkyl C34:3 (PC ae C34:3):, which were significantly down-regulated in PCOS group. In Figure 4, we present four metabolites' box plots, displaying the most visible difference between the PCOS and the control group.

Those results, as well as univariate ROC curve analysis, are demonstrated in Table 4. We used the ROC curve as an indicator of the highest discriminating potential, which we observed in Methionine sulfoxide (Met-SO) AUC (95\%CL) 0.82989 and Lysophosphatidylocholine acyl C 17:0 (lysoPC a C17:0) (AUC (95\%CL) 0.8292. 


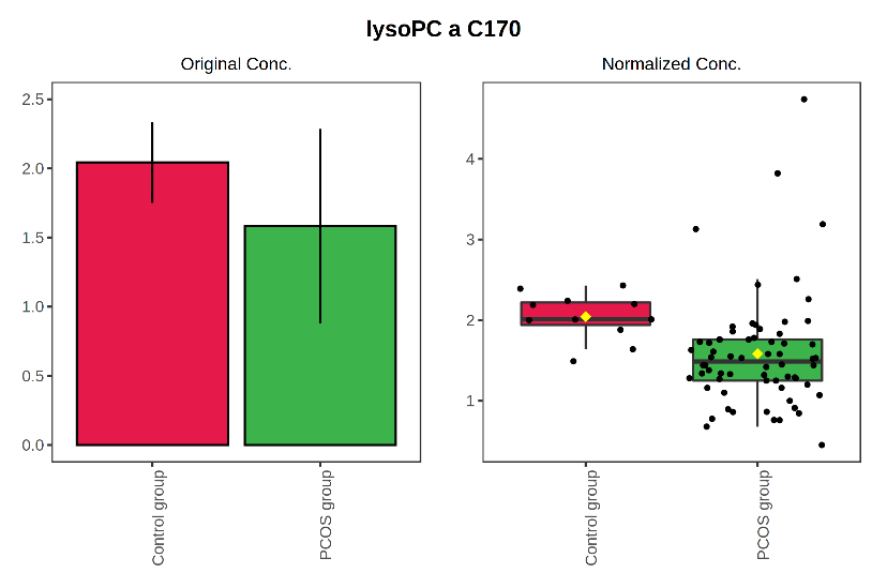

A

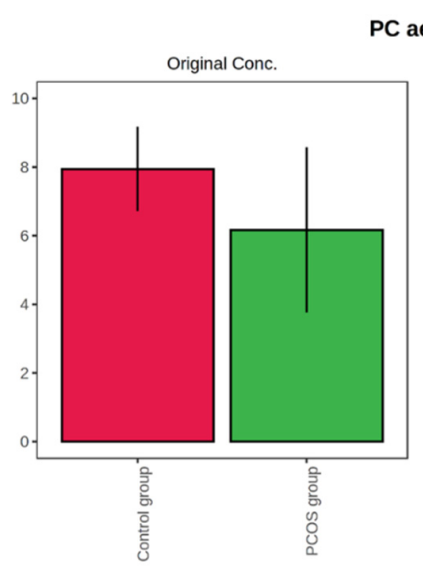

C

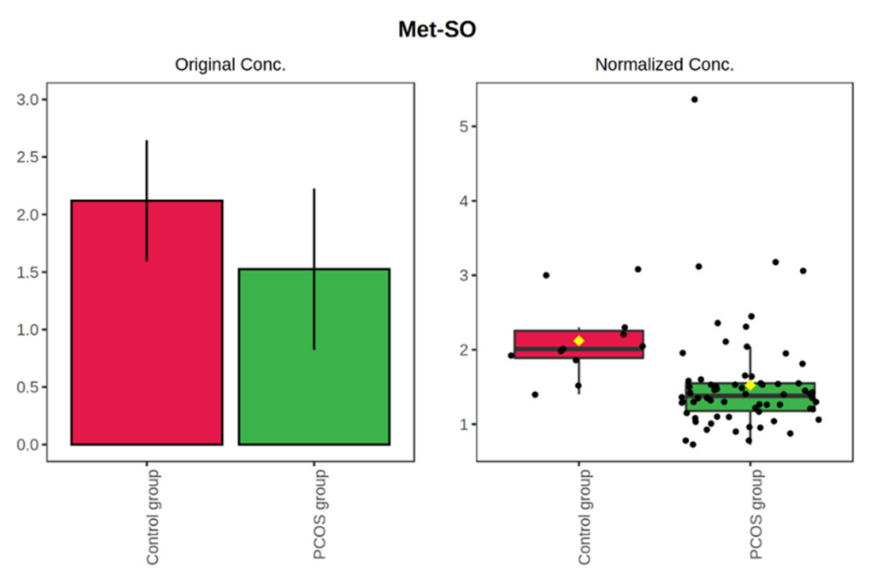

B

SM C181
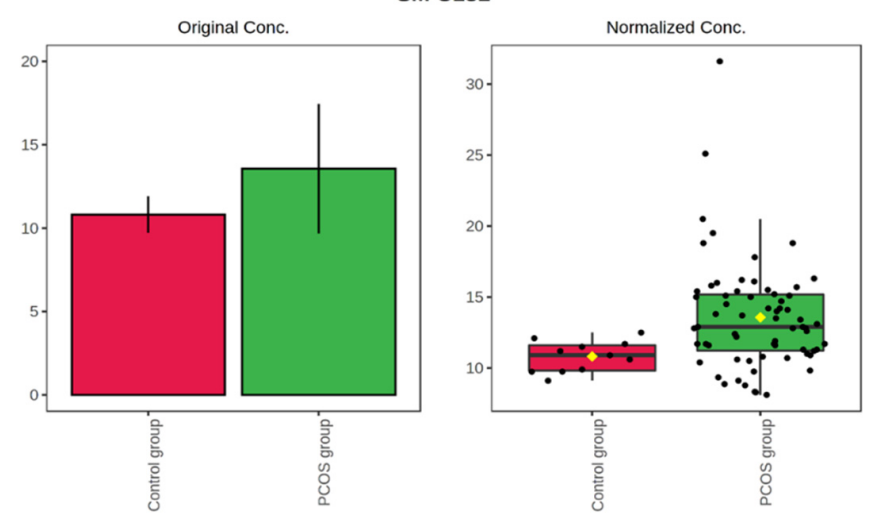

D

Figure 4. Box plots showing distributions of the selected metabolites across the studied groups. The bar charts on the left show the original values (mean $+/-\mathrm{SD}$ ). The box and whisker plots on the right summarize the normalized values. However, since these analyzes are univariate, therefore there was no data normalization. Thus, the original values and normalized values make the same values, only shown in two different types of graphs. (A) Lysophosphatidylcholine acyl C 17:0 (lyso PC a C17:0); (B) Methionine sulfoxide (Met-SO); (C) Phosphatidylcholine acyl-alkyl C34:3 (PC ae C34:3); (D) Sphingomyelin C18:1 (SM C18:1).

Table 4. List of differentiating metabolites with their serum concentrations determined in the whole PCOS group and control group (mean $\pm \mathrm{SD}, \mathrm{uM}$ ) and results from univariate statistics.

\begin{tabular}{|c|c|c|c|c|c|c|}
\hline Metabolite & Abbreviation & $\begin{array}{l}\text { PCOS Group } \\
\text { (Serum } \\
\text { Concentration) }\end{array}$ & $\begin{array}{c}\text { Control Group } \\
\text { (Serum } \\
\text { Concentration) }\end{array}$ & $p$-Value & Fold Change & AUC (95\%CI) \\
\hline $\begin{array}{c}\text { Phosphatidylocholine } \\
\text { acyl-acyl C36:5 }\end{array}$ & PC aа C36:5 & $21.59 \pm 11.27$ & $14.45 \pm 3.70$ & 0.0131 & 0.66901 & 0.73554 \\
\hline Methionine sulfoxide & Met-SO & $1.52 \pm 0.70$ & $2.12 \pm 0.53$ & 0.0005 & 1.3909 & 0.82989 \\
\hline $\begin{array}{l}\text { Lysophosphatidylcholine } \\
\text { acyl C 18:2 }\end{array}$ & lysoPC a C18:2 & $22.71 \pm 10.28$ & $31.48 \pm 9.11$ & 0.0074 & 1.3861 & 0.75413 \\
\hline $\begin{array}{c}\text { Phosphatidylcholine } \\
\text { acyl-alkyl C38:2 }\end{array}$ & PC ae C38:2 & $1.37 \pm 0.67$ & $1.82 \pm 0.67$ & 0.0187 & 1.3305 & 0.72314 \\
\hline $\begin{array}{l}\text { Phosphatidylocholine } \\
\text { acyl-acyl C40:5 }\end{array}$ & PC aa $C 40: 5$ & $8.99 \pm 3.74$ & $6.87 \pm 1.29$ & 0.0423 & 0.76456 & 0.69284 \\
\hline $\begin{array}{c}\text { Lysophosphatidylcholine } \\
\text { acyl C 17:0 }\end{array}$ & lysoPC a C17:0 & $1.58 \pm 0.70$ & $2.04 \pm 0.29$ & 0.0005 & 1.2908 & 0.8292 \\
\hline $\begin{array}{l}\text { Phosphatidylcholine } \\
\text { acyl-acyl C38:3 }\end{array}$ & PC aa C $38: 3$ & $47.16 \pm 16.38$ & $36.56 \pm 7.74$ & 0.0173 & 0.7753 & 0.7259 \\
\hline $\begin{array}{l}\text { Phosphatidylcholine } \\
\text { acyl-alkyl C34:3 }\end{array}$ & PC ae C34:3 & $6.17 \pm 2.41$ & $7.95 \pm 1.23$ & 0.0024 & 1.2882 & 0.78788 \\
\hline $\begin{array}{c}\text { Phosphatidylocholine } \\
\text { acyl-acyl C38:6 }\end{array}$ & PC aa C $38: 6$ & $72.64 \pm 26.86$ & $57.37 \pm 14.52$ & 0.0336 & 0.78983 & 0.70179 \\
\hline $\begin{array}{l}\text { Phosphatidylcholine } \\
\text { acyl-acyl C36:4 }\end{array}$ & PC aa C36:4 & $157.89 \pm 47.26$ & $125.18 \pm 17.19$ & 0.0058 & 0.79283 & 0.76171 \\
\hline Sphingomyelin C18:1 & SM C18:1 & $13.57 \pm 3.88$ & $10.82 \pm 1.10$ & 0.0044 & 0.79725 & 0.76977 \\
\hline
\end{tabular}


We made a similar comparison between two PCOS groups with 20 metabolites meeting the criteria (fold change threshold 1.25 and the $p$-value threshold 0.05) (Table 5). All the observed metabolites were up-regulated in the PCOS-2. The highest ROC AUC was observed in Phosphatidylcholine acyl-alkyl C34:3 (PC ae C34:3) (AUC 0.788); Phosphatidylcholine acyl-alkyl C40:4 (PC ae C40:4) (AUC 0.778); Phosphatidylcholine acyl-alkyl C40:5 (PC ae C40:5) (AUC 0.785) and Phosphatidylcholine acyl-alkyl C42:5 (PC ae C42:5) (AUC 0.774).

Table 5. Differentiating metabolites with serum concentrations determined between PCOS-1 and PCOS-2 (mean \pm SD, uM) and results from univariate statistics.

\begin{tabular}{|c|c|c|c|c|c|c|}
\hline Metabolite & Abbreviation & $\begin{array}{c}\text { PCOS-1 } \\
\text { (Serum } \\
\text { Concentration) }\end{array}$ & $\begin{array}{c}\text { PCOS-2 } \\
\text { (Serum } \\
\text { Concentration) }\end{array}$ & Fold Change & AUC (95\%CI) & $p$ \\
\hline $\begin{array}{l}\text { Lysophosphatidylcholine } \\
\text { acyl C 18:2 }\end{array}$ & lysoPC a C18:2 & $17.72 \pm 5.98$ & $22.47 \pm 9.35$ & 1.3861 & 0.75413 & 0.001 \\
\hline $\begin{array}{c}\text { Phosphatidylcholine } \\
\text { acyl-alkyl C34:3 }\end{array}$ & PC ae C34:3 & $5.31 \pm 2.04$ & $7.07 \pm 2.48$ & 1.2882 & 0.78788 & 0.0001 \\
\hline $\begin{array}{l}\text { Phosphatidylcholine } \\
\text { acyl-alkyl C44:5 }\end{array}$ & PC ae C44:5 & $1.72 \pm 0.65$ & $2.26 \pm 0.81$ & 1.3119 & 0.749 & 0.0001 \\
\hline $\begin{array}{l}\text { Phosphatidylcholine } \\
\text { acyl-alkyl C42:1 }\end{array}$ & PC ae C42:1 & $0.22 \pm 0.07$ & $0.28 \pm 0.12$ & 1.3037 & 0.73024 & 0.0003 \\
\hline $\begin{array}{l}\text { Phosphatidylcholine } \\
\text { acyl-alkyl C40:3 }\end{array}$ & PC ae $C 40: 3$ & $1.12 \pm 0.65$ & $1.45 \pm 1.34$ & 1.3026 & 0.626 & 0.066 \\
\hline $\begin{array}{l}\text { Phosphatidylcholine } \\
\text { acyl-alkyl C40:4 }\end{array}$ & PC ae C40:4 & $1.91 \pm 0.70$ & $2.48 \pm 0.93$ & 1.2974 & 0.77574 & 0.00001 \\
\hline Sphingomyelin C22:3 & SM C22:3 & $1.44 \pm 0.62$ & $1.85 \pm 0.63$ & 1.2919 & 0.713 & 0.0012 \\
\hline $\begin{array}{l}\text { Phosphatidylcholine } \\
\text { acyl-alkyl C } 34: 2\end{array}$ & PC ae C34:2 & $7.56 \pm 3.03$ & $9.74 \pm 3.81$ & 1.2885 & 0.71 & 0.013 \\
\hline $\begin{array}{l}\text { Phosphatidylcholine } \\
\text { acyl-alkyl C44:3 }\end{array}$ & PC ae C44:3 & $0.09 \pm 0.04$ & $0.12 \pm 0.05$ & 1.277 & 0.71 & 0.0008 \\
\hline $\begin{array}{l}\text { Phosphatidylcholine } \\
\text { acyl-alkyl C40:5 }\end{array}$ & PC ae C40:5 & $3.04 \pm 1.46$ & $3.88 \pm 1.62$ & 1.2768 & 0.785 & 0.00001 \\
\hline $\begin{array}{l}\text { Phosphatidylcholine } \\
\text { acyl-alkyl C42:4 }\end{array}$ & PC ae C42:4 & $0.77 \pm 0.28$ & $0.98 \pm 0.32$ & 1.2758 & 0.76057 & 0.00001 \\
\hline $\begin{array}{l}\text { Phosphatidylcholine } \\
\text { acyl-alkyl C44:6 }\end{array}$ & PC ae C44:6 & $1.06 \pm 0.40$ & $1.34 \pm 0.46$ & 1.2701 & 0.7284 & 0.0002 \\
\hline $\begin{array}{l}\text { Phosphatidylcholine } \\
\text { acyl-alkyl C38:2 }\end{array}$ & PC ae C38:2 & $1.21 \pm 0.55$ & $1.53 \pm 0.75$ & 1.3305 & 0.688 & 0.0046 \\
\hline $\begin{array}{l}\text { Lysophosphatidylcholine } \\
\text { acyl C 18:1 }\end{array}$ & lysoPC a C18:1 & $17.72 \pm 5.98$ & $22.47 \pm 9.35$ & 1.2681 & 0.664 & 0.015 \\
\hline Acylkarnitine C2 & $\mathrm{C} 2$ & $5.96 \pm 2.26$ & $7.49 \pm 4.09$ & 1.2603 & 0.571 & 0.336 \\
\hline $\begin{array}{l}\text { Phosphatidylcholine } \\
\text { acyl-alkyl C42:5 }\end{array}$ & PC ae C42:5 & $1.99 \pm 0.65$ & $2.50 \pm 0.68$ & 1.2589 & 0.7739 & 0.00001 \\
\hline $\begin{array}{l}\text { Lysophosphatidylcholine } \\
\text { acyl C 26:0 }\end{array}$ & lysoPC a C26:0 & $0.11 \pm 0.03$ & $0.13 \pm 0.07$ & 1.2547 & 0.659 & 0.02 \\
\hline $\begin{array}{l}\text { Phosphatidylcholine } \\
\text { acyl-alkyl C40:1 }\end{array}$ & PC ae C40:1 & $0.87 \pm 0.30$ & $1.09 \pm 0.39$ & 1.2514 & 0.689 & 0.002 \\
\hline $\begin{array}{l}\text { Phosphatidylcholine } \\
\text { acyl-alkyl C38:3 }\end{array}$ & PC ae C38:3 & $3.68 \pm 1.57$ & $4.60 \pm 2.93$ & 1.2511 & 0.601 & 0.15 \\
\hline $\begin{array}{l}\text { Lysophosphatidylcholine } \\
\text { acyl C 24:0 }\end{array}$ & lysoPC a C20:4 & $5.79 \pm 1.90$ & $7.24 \pm 2.62$ & 1.2507 & 0.693 & 0.00028 \\
\hline
\end{tabular}

We tried to seek some correlation between metabolome results and clinical parameters characteristic for PCOS patients and those that in many studies differ in PCOS groups compared to healthy controls and metabolome studies. We correlated waist circumference, WHR, fasting insulin, testosterone levels with selected metabolites. We found no significant correlation between those parameters. The strongest positive correlation was $R=0.23$ (Lysine and Testosterone), followed by $\mathrm{R}=0.225$ (acylcarnitine $\mathrm{C} 5$ and WHR), and the most apparent negative correlation we found between PC ae C343 and WHR R $=(-0.46)$ and $\mathrm{PC}$ ae $\mathrm{C} 343$ and waist circumference $\mathrm{R}=(-0.44)$.

\section{Discussion}

Metabolomics is an area of science covering comprehensive study and analysis of small-molecule metabolites in various biological systems that create specific organism 
individual patterns of molecules called metabolites. It is influenced by genetic background, environment, lifestyle, age, and diet, and therefore provides information about the state of a cell and/or organism [43]. The presented study examined women's metabolome to identify altered metabolite pathways that may provide new insight into PCOS's underlying biology. The study included patients with average body weight, as well as excess body weight and obesity. Imbalance in body weight and abdominal visceral adiposity is persistent in these women $[20,44]$. The tendency to generate androgen excess, abdominal adiposity, general obesity, insulin disturbances, and other metabolic syndrome symptoms in PCOS women may be altered already prenatally and in the early stages of life [44].

PCOS includes a lot of abnormalities, which influence several metabolic pathways. It is primarily characterized by disturbed metabolism of the steroid hormones, amino acids, carbohydrates, lipids, purines, and the citric acid cycle [29]. There are not many studies concerning the application of metabolomics in the field of PCOS. Most studies showed that altered metabolites in PCOS were primarily carbohydrate, fat, and protein metabolism [37,45-47].

In our study, the main differences between the studied population and controls were in the class of glycerophospholipids, which are one of the major components of cellular membranes, synthesized from glycerol-3-phosphate (G3P) in a de novo pathway that initially produces phosphatidic acid (PA) and diacylglycerol (DAG) or cytidine diphosphate-DAG (CDP-DAG) [48-50]. Those de novo pathways generate various types of glycerophospholipids. They differ with polar heads at the $s n-3$ position, like in the glycerol backbone and phosphatidylcholine (PC), phosphatidylethanolamine (PE), phosphatidylserine (PS), phosphatidylinositol (PI), phosphatidylglycerol (PG), and cardiolipin (CL) [51,52], and then further being remodeled in Lands' cycle [53].

In our PCOS group, up-regulation was observed in lysoPC a C18:2, PC ae C38:2, lysoPC a C17:0, PC ae C34:3. We noticed significant down-regulation of PC aa C36:5, PC aa C40:5, PC aa C40:6, PC aa C38:3, PC aa C38:6, PC aa C36:4. Haoula et al. [54] indicated mainly down-regulation of glycerophospholipids in the PCOS group. The results published by Zhao et al. [45] showed that all of the determined fatty acids are up-regulated in PCOS compared to controls. However, a contrary observation occurs in the case of phosphatidylcholine (PC), phosphatidylethanolamine (PE), and its derivatives lysophosphatidylcholine (LPC) and lysophosphatidylethanolamine (LPE). Those metabolites that include the glycophospholipids mentioned above are mainly decreased in PCOS. We know that lipids are the largest group of molecules and one of the most important ones whose metabolism differs in PCOS [29]. They are responsible for steroid hormone biosynthesis, metabolism of sphingolipids, and fatty acids. We did not find data in previous studies concerning particular metabolites, which were most significantly up-and down-regulated in our research. Nevertheless, previous studies reported decreased levels of similar metabolites: especially LPE (22:5) and LPC, mainly LPC (18:2) [55-57]. They take part in glucose metabolism. For example, decreased LPC concentration (18:2) shows the correlation between IR and the risk of developing type 2 diabetes mellitus. These are the disturbances to which women with PCOS seem to be more prone [55].

Nevertheless, similarly to those studies, we could not find a single lipid biomarker or a single pattern of plasma concentrations of lipids that could be characteristic of PCOS. We instead observed that there is a general difference in glycerophospholipids when compared to healthy controls.

Tonks et al., in their lipidomic study, indicated that lower levels of LysoPC correlate with insulin resistance, irrespective of body weight [58]. Interestingly, the whole PCOS group had lower concentrations of lysoPC a C18:2 and lysoPC a C17:0 than controls in our research. When we analyzed those metabolites when PCOS groups were divided according to body weight, women with normal body weight and PCOS had higher concentrations of lysoPC a C18:2, lysoPC a C26:0, lysoPC a C20:4, and lysoPC a C18:1, than overweight and obese women with PCOS. Thus, there was a difference between normal-weight PCOS and controls according to insulin resistance levels in our population, although BMI levels 
were similar. It seems that insulin resistance and body weight, and PCOS itself, might also impact the levels of LysoPC.

Acylkarnitines are oxidative metabolites, so-called by-products of non-complete fatty acid oxidation [59] built by fatty acid esterified to a carnitine molecule. Mitochondrial and peroxisomal enzymes synthesize them to transport long-chain fatty acids across the mitochondrial membrane for $\beta$-oxidation [60,61]. Dysregulation of fatty acid oxidation (FAO), known as lipotoxicity, is recognized as necessary in the pathophysiology of obesity, insulin resistance, and type 2 diabetes [62].

Muoio et al. proposed that acylcarnitines may play an alternative role in the induction of insulin resistance in glucose and lipid metabolism. They described a mechanism in which FAO rate outpaces the tricarboxylic acid cycle (TCA), which causes the accumulation of acylcarnitines, which may impact insulin sensitivity [63,64]. Acylcarnitines are formed mainly from FAO, but they may also be derived from almost any CoA ester [65], ketone bodies [66] degradation products of lysine, tryptophan, valine, leucine, and isoleucine, and carbon atoms from glucose (acetylcarnitine) [65]. From a physiological view, diets and fasting modulate the plasma acylcarnitine profile [67]. Michalik et al. stated that individual long-chain acylcarnitines were increased in obese and type 2 diabetes mellitus (T2DM) patients relative to lean controls. When they compared T2DM patients with thin and obese controls, diabetic patients had significantly elevated several levels. Additionally, in the group with diabetes, those with higher BMI had significant elevations of $\mathrm{C}_{4}-$ and $\mathrm{C}_{6}-\mathrm{CN}$ relative to lean subjects, although the mean values for $\mathrm{C}_{4}-\mathrm{CN}$ were nearly identical in obese controls and T2DM [62].

Interestingly, in our study, both the control group, which mainly consisted of lean women and normal-weight PCOS women, had significantly higher acylcarnitine $\mathrm{C} 2$ than obese women with PCOS. Furthermore, Newbern et al. reported that C2 acylcarnitine was divided by the sum of C3 and C5, inversely correlated with HOMA-IR [68], which would be in line with our observations that the highest concentrations of $\mathrm{C} 2$ were in the control group, with the lowest HOMA-IR.

We also observed a significant difference in the concentration of Sphingomyelin C18:1 between the PCOS group and controls. Sphingomyelins are a part of an involved family of sphingolipids, which take part in various biological processes such as cell proliferation, differentiation, apoptosis, migration; membrane trafficking; cell-cell interactions; and cell morphology, as well as both intracellular and extracellular signaling [69,70]. Bikmann et al. indicated that changes in the levels of sphingolipids directly affect the intensity of insulin signaling; depending on the type of sphingolipid, they either promote insulin resistance or enhance the insulin signaling and thus inhibit insulin resistance [71]. Hanamatsu et al. suggested that SM with long saturated acyl chains (18:0, 20:0, 22:0, and 24:0) are involved in developing the metabolic syndrome and its indices such as abnormal lipid profile, obesity, and IR [72]. Li et al. and Haoula et al. observed notable elevation in the sphingomyelin levels in PCOS patients. In the presented study, we noticed a significant increase in the concentration of Sphingomyelin C18:1 in all the patients with PCOS in comparison to Controls. Thus, SM seems to be involved in the pathogenesis of PCOS [73]. BMI does not seem to have an impact on the concentration of SM.

Our study observed significant differences in glycerophospholipid concentrations between the PCOS and the control group. Still, there is no one specific pattern of either up or down-regulation of those compounds.

These observations that present the metabolomic changes between obese and lean women with PCOS for the first time are the most important findings of our study and might indicate new directions for further research on the PCOS population.

\section{Conclusions}

- Our study observed the main differences in glycerophospholipid concentrations but no specific pattern of either up or down-regulation of those compounds. 
- We see a tendency to different glycerophospholipids concentrations in PCOS than in a healthy population than a general elevation or decrease.

- Metabolic changes such as insulin resistance and elevated body weight seem to influence acylcarnitine $\mathrm{C} 2$ levels more significantly than PCOS itself.

- $\quad$ SM C18:1 should be more intensively observed and examined in future studies and may serve as one of the PCOS biomarkers.

\begin{abstract}
Author Contributions: Conceptualization, K.O., S.P. and J.M.; methodology, K.O., L.P., S.P., J.M.; formal analysis, K.O., S.P., J.M.; investigation, K.O., U.M.; resources, K.O., L.P., U.M.; data curation, K.O., U.M.; writing—original draft preparation, K.O.; writing—review and editing, K.O., S.P., and J.M.; visualization, K.O.; supervision, L.P. and J.M.; project administration, L.P.; funding acquisition, K.O. and L.P. All authors have read and agreed to the published version of the manuscript.
\end{abstract}

Funding: This research received no external funding.

Institutional Review Board Statement: The study was conducted according to the guidelines of the Declaration of Helsinki and approved by the Ethics Committee of Poznan University of Medical Sciences (protocol code number $741 / 20$ from 7 th of November 2020).

Informed Consent Statement: Informed consent was obtained from all subjects involved in the study. Data Availability Statement: Not applicable.

Conflicts of Interest: The authors declare no conflict of interest.

\title{
References
}

1. Norman, R.J.; Dewailly, D.; Legro, R.S. Polycystic ovary syndrome. Lancet 2007, 370, 685-697. [CrossRef]

2. Fenkci, V.; Fenkci, S.; Yilmazer, M.; Serteser, M. Decreased total antioxidant status and increased oxidative stress in women with polycystic ovary syndrome may contribute to the risk of cardiovascular disease. Fertil. Steril. 2003, 80, 123-127. [CrossRef]

3. Escobar-Morreale, H.F.; Luque-Ramírez, M.; MillánJ, L.S. The Molecular-Genetic Basis of Functional Hyperandrogenism and the Polycystic Ovary Syndrome. Endocr. Rev. 2005, 26, 251-282. [CrossRef] [PubMed]

4. The Rotterdam ESHRE/ASRM-sponsored PCOS consensus workshop group Revised 2003 consensus on diagnostic criteria and long-term health risks related to polycystic ovary syndrome (PCOS). Hum. Reprod. 2004, 19, 41-47. [CrossRef]

5. Zawadski, J.K. Diagnostic Criteria for Polycystic Ovary Syndrome: Towards a Rational Approach; Polycystic Ovary Synddrome; Blackwell Scientific: Boston, MA, USA, 1992; pp. 377-384.

6. Chang, J.; Azziz, R.; Legro, R.; Dewailly, D.; Franks, S.; Tarlatzis, R.; Fauser, B.; Balen, A.; Bouchard, P.; Dalgien, E.; et al. Revised 2003 consensus on diagnostic criteria and long-term health risks related to polycystic ovary syndrome. Fertil. Steril. 2004, 81, 19-25. [CrossRef]

7. Lujan, M.E.; Chizen, D.R.; Pierson, R. Diagnostic Criteria for Polycystic Ovary Syndrome: Pitfalls and Controversies. J. Obs. Gynaecol. Can. 2008, 30, 671-679. [CrossRef]

8. Azziz, R.; Carmina, E.; Dewailly, D.; Diamanti-Kandarakis, E.; Escobar-Morreale, H.F.; Futterweit, W. Positions statement: Criteria for defining polycystic ovary syndrome as a predominantly hyperandrogenic syndrome: An Androgen Excess Soci-ety guideline. J. Clin. Endocrinol. Metab. 2006, 91, 4237-4245. [CrossRef]

9. Azziz, R.; Woods, K.S.; Reyna, R.; Key, T.J.; Knochenhauer, E.S.; Yildiz, B.O. The Prevalence and Features of the Polycystic Ovary Syndrome in an Unselected Population. J. Clin. Endocrinol. Metab. 2004, 89, 2745-2749. [CrossRef] [PubMed]

10. Goodarzi, M.O.; Dumesic, D.A.; Chazenbalk, G.; Azziz, R. Polycystic ovary syndrome: Etiology, pathogenesis and diagnosis. Nat. Rev. Endocrinol. 2011, 7, 219-231. [CrossRef]

11. Diamanti-Kandarakis, E.; Kouli, C.R.; Bergiele, A.T.; Filandra, F.A.; Tsianateli, T.C.; Spina, G.G.; Zapanti, E.D.; Bartzis, M.I. A Survey of the Polycystic Ovary Syndrome in the Greek Island of Lesbos: Hormonal and Metabolic Profile. J. Clin. Endocrinol. Metab. 1999, 84, 4006-4011. [CrossRef] [PubMed]

12. Ozegowska, K.; Pawelczyk, L. Cardiometabolic risk in patients with polycystic ovary syndrome. Ginekol. Pol. 2015, 86. [CrossRef]

13. March, W.A.; Moore, V.M.; Willson, K.J.; Phillips, D.I.; Norman, R.J.; Davies, M.J. The prevalence of polycystic ovary syndrome in a community sample assessed under contrasting diagnostic criteria. Hum. Reprod. 2009, 25, 544-551. [CrossRef]

14. Boyle, A.J.; Cunningham, J.; O'dea, K.; Dunbar, T.; Norman, R.J. Prevalence of polycystic ovary syndrome in a sample of Indigenous women in Darwin, Australia. Med. J. Aust. 2012, 196, 62-66. [CrossRef]

15. Azziz, R. Androgen excess is the key element in polycystic ovary syndrome. Fertil. Steril. 2003, 80, 252-254. [CrossRef]

16. Teede, H.J.; Misso, M.L.; Costello, M.F.; Dokras, A.; Laven, J.; Moran, L.; Piltonen, T.; Norman, R.; Andersen, M.; Azziz, R.; et al. Recommendations from the international evidence-based guideline for the assessment and management of polycystic ovary syndrome. Fertil. Steril. 2018, 110, 364-379. [CrossRef] [PubMed] 
17. Blank, S.; McCartney, C.; Marshall, J. The origins and sequelae of abnormal neuroendocrine function in polycystic ovary syndrome. Hum. Reprod. Updat. 2006, 12, 351-361. [CrossRef] [PubMed]

18. Diamanti-Kandarakis, E.; Dunaif, A. Insulin Resistance and the Polycystic Ovary Syndrome Revisited: An Update on Mechanisms and Implications. Endocr. Rev. 2012, 33, 981-1030. [CrossRef] [PubMed]

19. Gambineri, A.; Pelusi, C.; Vicennati, V.; Pagotto, U.; Pasquali, R. Obesity and the polycystic ovary syndrome. Int. J. Obes. 2002, 26, 883-896. [CrossRef]

20. Carmina, E.; Bucchieri, S.; Esposito, A.; Del Puente, A.; Mansueto, P.; Orio, F.; Di Fede, G.; Rini, G. Abdominal Fat Quantity and Distribution in Women with Polycystic Ovary Syndrome and Extent of Its Relation to Insulin Resistance. J. Clin. Endocrinol. Metab. 2007, 92, 2500-2505. [CrossRef]

21. Escobar-Morreale, H.F.; Millán, J.L.S. Abdominal adiposity and the polycystic ovary syndrome. Trends Endocrinol. Metab. 2007, 18, 266-272. [CrossRef]

22. National Institutes of Health Evidence-based Methodology Workshop on Polycystic Ovary Syndrome. 2012. Available online: https://prevention.nih.gov/research-priorities/research-needs-and-gaps/pathways-prevention/evidence-basedmethodology-workshop-polycystic-ovary-syndrome-pcos (accessed on 20 January 2021).

23. Zhang, L.; Fang, X.; Li, L.; Liu, R.; Zhang, C.; Liu, H.; Tan, M.; Yang, G. The association between circulating irisin levels and different phenotypes of polycystic ovary syndrome. J. Endocrinol. Investig. 2018, 41, 1401-1407. [CrossRef] [PubMed]

24. Minooee, S.; Tehrani, F.R.; Tohidi, M.; Azizi, F. Role of androgen ratios in the prediction of the metabolic phenotype in polycystic ovary syndrome. Int. J. Gynecol. Obs. 2017, 137, 110-115. [CrossRef]

25. Ożga, K.; Sendrakowska, M.K.; Dydejczyk, A.H.; Gilis-Januszewska, A.; Ratajczak, M.; Ratajczak, M.; Chaykivska, Z.; Jach, R. The value of the free androgen index depends on the phenotype of polycystic ovary syndrome-A single-centre experience. Endokrynol. Pol. 2019, 70, 330-335. [CrossRef]

26. Tal, R.; Seifer, D.; Khanimov, M.; Malter, H.E.; Grazi, R.V.; Leader, B. Characterization of women with elevated antimüllerian hormone levels (AMH): Correlation of AMH with polycystic ovarian syndrome phenotypes and assisted reproductive technology outcomes. Am. J. Obs. Gynecol. 2014, 211, 59.e1-59.e8. [CrossRef]

27. Serkova, N.J.; Standiford, T.J.; Stringer, K.A. The Emerging Field of Quantitative Blood Metabolomics for Biomarker Discovery in Critical Illnesses. Am. J. Respir. Crit. Care Med. 2011, 184, 647-655. [CrossRef]

28. Zhang, W.; Sun, G.; Likhodii, S.; Liu, M.; Aref-Eshghi, E.; Harper, P.; Martin, G.; Furey, A.; Green, R.; Randell, E.; et al. Metabolomic analysis of human plasma reveals that arginine is depleted in knee osteoarthritis patients. Osteoarthr. Cart. 2016, 24, 827-834. [CrossRef] [PubMed]

29. Rajska, A.; Buszewska-Forajta, M.; Rachoń, D.; Markuszewski, M.J. Metabolomic Insight into Polycystic Ovary Syndrome-An Overview. Int. J. Mol. Sci. 2020, 21, 4853. [CrossRef] [PubMed]

30. Doerr, A. Global metabolomics. Nat. Chem. Biol. 2017, 14, 32. [CrossRef]

31. Nicholson, J.; Lindon, J. Metabonomics. Nat. Cell Biol. 2008, 455, 1054-1056. [CrossRef]

32. Khamis, M.M.; Adamko, D.J.; El-Aneed, A. Mass spectrometric based approaches in urine metabolomics and biomarker discovery. Mass Spectrom. Rev. 2017, 36, 115-134. [CrossRef] [PubMed]

33. Kovac, J.R.; Pastuszak, A.; Lamb, D.J. The use of genomics, proteomics, and metabolomics in identifying biomarkers of male infertility. Fertil. Steril. 2013, 99, 998-1007. [CrossRef] [PubMed]

34. Carmina, E.; Azziz, R. Diagnosis, phenotype, and prevalence of polycystic ovary syndrome. Fertil. Steril. 2006, 86, S7-S8. [CrossRef]

35. Murri, M.; Insenser, M.; Escobar-Morreale, H.F. Metabolomics in polycystic ovary syndrome. Clin. Chim. Acta 2014, 429, 181-188. [CrossRef] [PubMed]

36. Atiomo, W.; A Bates, S.; E Condon, J.; Shaw, S.; West, J.H.; Prentice, A.G. The plasminogen activator system in women with polycystic ovary syndrome. Fertil. Steril. 1998, 69, 236-241. [CrossRef]

37. Sun, L.; Hu, W.; Liu, Q.; Hao, Q.; Sun, B.; Zhang, Q.; Mao, S.; Qiao, J.; Yan, X. Metabonomics Reveals Plasma Metabolic Changes and Inflammatory Marker in Polycystic Ovary Syndrome Patients. J. Proteome Res. 2012, 11, 2937-2946. [CrossRef] [PubMed]

38. Jeyasuria, P.; Ikeda, Y.; Jamin, S.; Zhao, L.; de Rooij, D.; Themmen, A.P.N.; Behringer, R.R.; Parker, K.L. Cell-Specific Knockout of Steroidogenic Factor 1 Reveals Its Essential Roles in Gonadal Function. Mol. Endocrinol. 2004, 18, 1610-1619. [CrossRef]

39. Jonard, S.; Robert, Y.; Cortet-Rudelli, C.; Pigny, P.; Decanter, C.; Dewailly, D. Ultrasound examination of polycystic ovaries: Is it worth counting the follicles? Hum. Reprod. 2003, 18, 598-603. [CrossRef]

40. WHO. Obesity: Preventing and managing the global epidemic. Report of a WHO consultation. World Health Organ. Tech. Rep. Ser. 2000, 894, 1-253. Available online: http:/ / www.ncbi.nlm.nih.gov/pubmed/11234459 (accessed on 20 January 2021).

41. Siskos, A.P.; Jain, P.; Römisch-Margl, W.; Bennett, M.; Achaintre, D.; Asad, Y.; Marney, L.; Richardson, L.; Koulman, A.; Griffin, J.L.; et al. Interlaboratory Reproducibility of a Targeted Metabolomics Platform for Analysis of Human Serum and Plasma. Anal. Chem. 2017, 89, 656-665. [CrossRef] [PubMed]

42. Chong, J.; Soufan, O.; Li, C.; Caraus, I.; Li, S.; Bourque, G.; Wishart, D.S.; Xia, J. MetaboAnalyst 4.0: Towards more transparent and integrative metabolomics analysis. Nucleic Acids Res. 2018, 46, W486-W494. [CrossRef] [PubMed]

43. Dunn, W.B.; Broadhurst, D.I.; Atherton, H.J.; Goodacre, R.; Griffin, J.L. Systems level studies of mammalian metabolomes: The roles of mass spectrometry and nuclear magnetic resonance spectroscopy. Chem. Soc. Rev. 2011, 40, 387-426. [CrossRef] 
44. Borruel, S.; Fernández-Durán, E.; Alpañés, M.; Martí, D.; Álvarez-Blasco, F.; Luque-Ramírez, M.; Escobar-Morreale, H.F. Global Adiposity and Thickness of Intraperitoneal and Mesenteric Adipose Tissue Depots Are Increased in Women With Polycystic Ovary Syndrome (PCOS). J. Clin. Endocrinol. Metab. 2013, 98, 1254-1263. [CrossRef]

45. Zhao, Y.; Fu, L.; Li, R.; Wang, L.-N.; Yang, Y.; Liu, N.-N.; Zhang, C.-M.; Wang, Y.; Liu, P.; Tu, B.-B.; et al. Metabolic profiles characterizing different phenotypes of polycystic ovary syndrome: Plasma metabolomics analysis. Bmc Med. 2012, 10, 153. [CrossRef] [PubMed]

46. Atiomo, W.; Daykin, C.A. Metabolomic biomarkers in women with polycystic ovary syndrome: A pilot study. Mol. Hum. Reprod. 2012, 18, 546-553. [CrossRef]

47. Escobar-Morreale, H.F.; Samino, S.; Insenser, M.; Vinaixa, M.; Luque-Ramírez, M.; Lasunción, M.A.; Correig, X. Metabolic Heterogeneity in Polycystic Ovary Syndrome Is Determined by Obesity: Plasma Metabolomic Approach Using GC-MS. Clin. Chem. 2012, 58, 999-1009. [CrossRef]

48. Hishikawa, D.; Hashidate, T.; Shimizu, T.; Shindou, H. Diversity and function of membrane glycerophospholipids generated by the remodeling pathway in mammalian cells. J. Lipid Res. 2014, 55, 799-807. [CrossRef]

49. Kennedy, E.P. The biological synthesis of phospholipids. Can. J. Biochem. Physiol. 1956, 34. [CrossRef]

50. Holub, B.; Kuksis, A. Metabolism of Molecular Species of Diacylglycerophospholipids. Adv. Lipid Res. 1978, 16, 1-125. [CrossRef] [PubMed]

51. Van Meer, G.; Voelker, D.R.; Feigenson, G.W. Membrane lipids: Where they are and how they behave. Nat. Rev. Mol. Cell Biol. 2008, 9, 112-124. [CrossRef] [PubMed]

52. Yamashita, A.; Hayashi, Y.; Nemoto-Sasaki, Y.; Ito, M.; Oka, S.; Tanikawa, T.; Waku, K.; Sugiura, T. Acyltransferases and transacylases that determine the fatty acid composition of glycerolipids and the metabolism of bioactive lipid mediators in mammalian cells and model organisms. Prog. Lipid Res. 2014, 53, 18-81. [CrossRef]

53. Lands, W.E. Metabolism of glycerolipides: A comparison of lecithin and triglyceride synthesis. J. Biol. Chem. 1958, 231, 883-888. [CrossRef]

54. Haoula, Z.; Ravipati, S.; Stekel, D.J.; Ortori, C.A.; Hodgman, C.; Daykin, C.; Raine-Fenning, N.; Barrett, D.A.; Atiomo, W. Lipidomic analysis of plasma samples from women with polycystic ovary syndrome. Metabolomics 2014, 11, 657-666. [CrossRef] [PubMed]

55. Zhao, X.; Xu, F.; Qi, B.; Hao, S.; Li, Y.; Li, Y.; Zou, L.; Lu, C.; Xu, G.; Hou, L. Serum Metabolomics Study of Polycystic Ovary Syndrome Based on Liquid Chromatography-Mass Spectrometry. J. Proteome Res. 2014, 13, 1101-1111. [CrossRef]

56. Whigham, L.D.; Butz, D.E.; Dashti, H.; Tonelli, M.; Johnson, L.K.; Cook, M.E.; Porter, W.P.; Eghbalnia, H.R.; Markley, J.L.; Lindheim, S.R.; et al. Metabolic Evidence of Diminished Lipid Oxidation in Women with Polycystic Ovary Syndrome. Curr. Metab. 2014, 2, 269-278. [CrossRef]

57. Escobar-Morreale, H.F.; Villuendas, G.; Botella-Carretero, J.I.; Álvarez-Blasco, F.; Sanchón, R.; Luque-Ramírez, M.; Millán, J.L.S. Adiponectin and resistin in PCOS: A clinical, biochemical and molecular genetic study. Hum. Reprod. 2006, 21, 2257-2265. [CrossRef]

58. Tonks, K.T.; Coster, A.C.; Christopher, M.J.; Chaudhuri, R.; Xu, A.; Gagnon-Bartsch, J.; Chisholm, D.J.; James, D.; Meikle, P.J.; Greenfield, J.R.; et al. Skeletal muscle and plasma lipidomic signatures of insulin resistance and overweight/obesity in humans. Obesity 2016, 24, 908-916. [CrossRef]

59. Ritter, O.; Jelenik, T.; Roden, M. Lipid-mediated muscle insulin resistance: Different fat, different pathways? J. Mol. Med. 2015, 93, 831-843. [CrossRef] [PubMed]

60. Reuter, S.E.; Evans, A.M. Carnitine and Acylcarnitines. Clin. Pharm. 2012, 51, 553-572. [CrossRef]

61. Lawrence Merritt, J., 2nd; Norris, M.; Kanungo, S. Fatty acid oxidation disorders. Ann Transl Med. 2018, 6, 473. [CrossRef] [PubMed]

62. Mihalik, S.J.; Goodpaster, B.H.; Kelley, D.E.; Chace, D.H.; Vockley, J.; Toledo, F.G.; Delany, J.P. Increased Levels of Plasma Acylcarnitines in Obesity and Type 2 Diabetes and Identification of a Marker of Glucolipotoxicity. Obesity 2010, 18, 1695-1700. [CrossRef]

63. Muoio, D.M.; Neufer, P.D. Lipid-Induced Mitochondrial Stress and Insulin Action in Muscle. Cell Metab. 2012, 15, 595-605. [CrossRef]

64. Muoio, D.M.; Koves, T.R. Lipid-induced metabolic dysfunction in skeletal muscle. Novartis Found. Symp. 2007, 286, 24-46. [CrossRef]

65. Rinaldo, P.; Cowan, T.M.; Matern, D. Acylcarnitine profile analysis. Genet. Med. 2008, 10, 151-156. [CrossRef]

66. Soeters, M.R.; Serlie, M.J.; Sauerwein, H.P.; Duran, M.; Ruiter, J.P.; Kulik, W.; Ackermans, M.T.; Minkler, P.E.; Hoppel, C.L.; Wanders, R.J.A.; et al. Characterization of D-3-hydroxybutyrylcarnitine (ketocarnitine): An identified ketosis-induced metabolite. Metabolism 2012, 61, 966-973. [CrossRef]

67. Schooneman, M.G.; Vaz, F.; Houten, S.; Soeters, M.R. Acylcarnitines. Diabetes 2012, 62, 1-8. [CrossRef] [PubMed]

68. Newbern, D.; Balikcioglu, P.G.; Balikcioglu, M.; Bain, J.R.; Muehlbauer, M.; Stevens, R.; Ilkayeva, O.; Dolinsky, D.; Armstrong, S.; Irizarry, K.; et al. Sex Differences in Biomarkers Associated with Insulin Resistance in Obese Adolescents: Metabolomic Profiling and Principal Components Analysis. J. Clin. Endocrinol. Metab. 2014, 99, 4730-4739. [CrossRef] [PubMed]

69. Lahiri, S.; Lee, H.; Mesicek, J.; Fuks, Z.; Haimovitz-Friedman, A.; Kolesnick, R.N. Kinetic characterization of mammalian ceramide synthases: Determination of Km values towards sphinganine. FEBS Lett. 2007. [CrossRef]

70. Merrill, A.H.; Wang, M.D.; Park, M.; Sullards, M.C. (Glyco)sphingolipidology: An amazing challenge and opportunity for systems biology. Trends Biochem. Sci. 2007, 32, 457-468. [CrossRef]

71. Bikman, B.T. A role for sphingolipids in the pathophysiology of obesity-induced inflammation. Cell. Mol. Life Sci. 2012, 69, 2135-2146. [CrossRef] [PubMed] 
72. Hanamatsu, H.; Ohnishi, S.; Sakai, S.; Yuyama, K.; Mitsutake, S.; Takeda, H.; Hashino, S.; Igarashi, Y. Altered levels of serum sphingomyelin and ceramide containing distinct acyl chains in young obese adults. Nutr. Diabetes 2014, 4, e141. [CrossRef]

73. Li, J.; Xie, L.-M.; Song, J.-L.; Yau, L.-F.; Mi, J.-N.; Zhang, C.-R.; Wu, W.-T.; Lai, M.-H.; Jiang, Z.-H.; Wang, J.-R.; et al. Alterations of Sphingolipid Metabolism in Different Types of Polycystic Ovary Syndrome. Sci. Rep. 2019, 9, 3204. [CrossRef] [PubMed] 